19

\title{
Влияние локализованных плазмонов в тонких пленках серебра и золота на оптические свойства органических красителей в акрилатной полимерной матрице*
}

\author{
(C) К.И. Князев, Р.Е. Якуненков, Н.А. Зулина, М.И. Фокина, \\ Р.Д. Набиуллина, Н.А. Торопов
}

Университет ИТМО, 197101 Санкт-Петербург, Россия

e-mail: kniazevkrll@gmail.com

Поступила в редакцию 27.06.2018 г.

\begin{abstract}
Приведены результаты исследования влияния локализованного поверхностного плазмонного резонанса наночастиц золота и серебра на излучательную способность органических красителей: 2-4-Диметиламиностирил-1-метилпиридиниум (2-(4-(Dimethylamino)styryl)-1-methylpyridinium, DSM) и Родамин В (RB) в полимерной матрице на основе акрилатов, сформированной на поверхности островковых металлических пленок с помощью метода УФ литографии. Показано, что наличие плазмонного резонанса значительно усиливает как оптическое поглощение, так и интенсивность флуоресценции органических красителей в полимерной матрице.
\end{abstract}

DOI: $10.21883 /$ OS.2018.10.46711.187-18

\section{Введение}

Органические люминесцирующие материалы и композиты на их основе широко исследуются в связи с перспективными направлениями их применения в качестве активных элементов органических светодиодов (OLED), сенсоров, оптических ограничителей, твердотельных лазеров на органических красителях, микролазерах и т. д., так как являются сравнительно недорогими, легкими, гибкими оптическим материалами со спектральным диапазоном от ближнего УФ до дальнего ИК. По своим характеристикам они значительно превосходят аналогичные параметры некоторых неорганических материалов [1]. Особую актуальность приобретают исследования, направленные на модификацию и управление их оптическими характеристиками, а также усиление излучательной способности, в том числе и с использованием плазмонного резонанса металлических наноструктур [2]. Кроме того, исследования в данном направлении предшествуют расчетам и экспериментам, посвященным улучшению генерационных характеристик микроэлементов интегральной оптики - микролазеров на основе органических красителей, а также созданию спазеров, перспективных для применений в биомедицине $[3,4]$.

Локализованный поверхностный плазмон, представляющий собой коллективное колебание электронов проводимости в металлических наночастицах, способен усиливать излучательную способность полупроводниковых и органических материалов [5,6]. Кроме того, использование наночастиц благородных металлов ( $\mathrm{Au}$ и $\mathrm{Ag})$

* The 1st International School-cinference for young researchers „Smart nanosystems for translation medicine“, November 28-29, 2017, St. Petersburg, Russia. позволяет наблюдать лазерную генерацию органических излучающих элементов благодаря эффекту усиленного локализованного электромагнитного поля [7]. Однако прямой контакт молекулы органического красителя с металлическими наночастицами имеет нежелательное свойство тушения флуоресценции, которого можно избежать с помощью создания буферного слоя, диэлектрического зазора между молекулой красителя и плазмонной наночастицей. Эту функцию могут успешно выполнять полимерные композиты.

Применимость того или иного полимерного материала в качестве матрицы для твердотельных элементов на основе органических красителей определяется совместимостью красителя с полимером, а также отсутствием влияния матрицы на излучательную способность молекул красителя, прозрачностью в области их оптического поглощения и флуоресценции. Немаловажную роль играет обеспечение фотостабильности органических материалов за счет диссипации тепловой энергии полимерными цепями.

Предыдущие исследования показали перспективность акрилатов для оптического применения [8]. Разнообразие акрилатов позволяет подобрать матрицу с определенными оптическими (показатель преломления, прозрачность) и физико-механическими (прочность, твердость) характеристиками, а также дает возможность создавать элементы различных форм и размеров благодаря применению прецизионных фотолитографических методов. Данная возможность важна для развития оптических технологий при создании миниатюрных и многофункциональных элементов, не имеющих сборных частей и не требующих настройки, производимых по планарной технологии. 
Несмотря на то, что усиление люминесценции различных флуорофоров было ранее продемонстрировано, механизмы его все еще не изучены детально. В частности, известно, что ближнее поле наночастиц является быстро затухающим и действует на расстояниях, сравнимых с их размерами. Таким образом, следует соблюдать некоторую оптимальную дистанцию между частицами и органическими молекулами, при которой тушение будет минимально, а эффект ближнего поля все еще сохранится. Помимо пространственного совмещения, следует иметь в виду и спектральную близость электронных переходов молекул и плазмонных резонансов наночастиц.

Целью работы является исследование влияния плазмонного резонанса, локализованного в частицах золота и серебра, на оптические свойства двух органических красителей с различным спектральным положением полос молекулярного поглощения в полимерной матрице на основе смеси акрилатов.

\section{Материалы и методы}

Пленки золота формировались на поверхности стеклянной подложки методом магнетронного распыления с последующим отжигом пленки при температуре $200^{\circ} \mathrm{C}$ в течение $10 \mathrm{~min}$. Пленки серебра были получены на кварцевой подложке в вакуумной камере PVD 75 Kurt J. Lesker при остаточном давлении газов в камере $\sim 10^{-7}$ Torr. Толщина пленки серебра контролировалась с помощью кварцевых микровесов и составляла $4 \mathrm{~nm}$. После нанесения серебра пленки отжигались $20 \mathrm{~min}$ при температуре $200^{\circ} \mathrm{C}$.

Согласно данным, полученным с помощью сканирующий электронной микроскопии, сформированные пленки представляют собой неоднородные ансамбли островковых наноструктур. Изображения аналогичных структур были продемонстрированы, например, в [9].

Чтобы отдалить молекулы красителей от поверхности металлических частиц, красители были диспергированы в полимерной матрице. Для ее создания использовалась композиция: изодецилакрилат, 1,6-гександиолдиакрилат и 2 карбоксиэтилакрилат в массовом соотношении $45: 45: 10$. Фотоинициатором для УФ полимеризации являлся 2,2-диметокси-2фенилацетофенон с массовой долей $0.5 \%$. Концентрация красителей в полимерной матрице составила $0.05 \%$ по массе.

Жидкая мономерная композиция с красителем наносилась на поверхность подготовленных подложек, после чего происходило формирование твердой полимерной пленки методом контактной УФ полимеризации $(365 \mathrm{~nm})$. Толщина полимерной пленки около $50 \mu \mathrm{m}$.

Показатель преломления полимерной матрицы был измерен с помощью рефрактометра Аббе и составил 1.4898. Прозрачность пленок составляла порядка 90\% при толщине $100 \mu \mathrm{m}$.
Спектры оптического поглощения были получены методом спектроскопии видимой и УФ областей (UV-Vis спектрофотометр Shimadzu 1800), а спектры флуоресценции - с помощью спектрофлуориметра Shimadzu RF-5301 PC при возбуждении на длинах волн 500 и $530 \mathrm{~nm}$.

\section{Результаты и обсуждение}

На рис. 1, $a$ приведены спектры оптического поглощения DSM в полимерной матрице, а также спектры этих полимеров на тонком слое из наночастиц золота. Следует отметить, что сумма оптических плотностей красителя в полимерной матрице и пленки золота (кривая 4) не равна оптической плотности красителя в матрице, непосредственно нанесенных на слой золота. В случае, когда молекулы расположены на золотой пленке, оптическая плотность больше, даже с учетом того, что отражение от подложек, на которых нанесены образцы, учитывается при математическом сложении дважды. Это свидетельствует о взаимном влиянии молекул красителя и золотой пленки в такой системе.
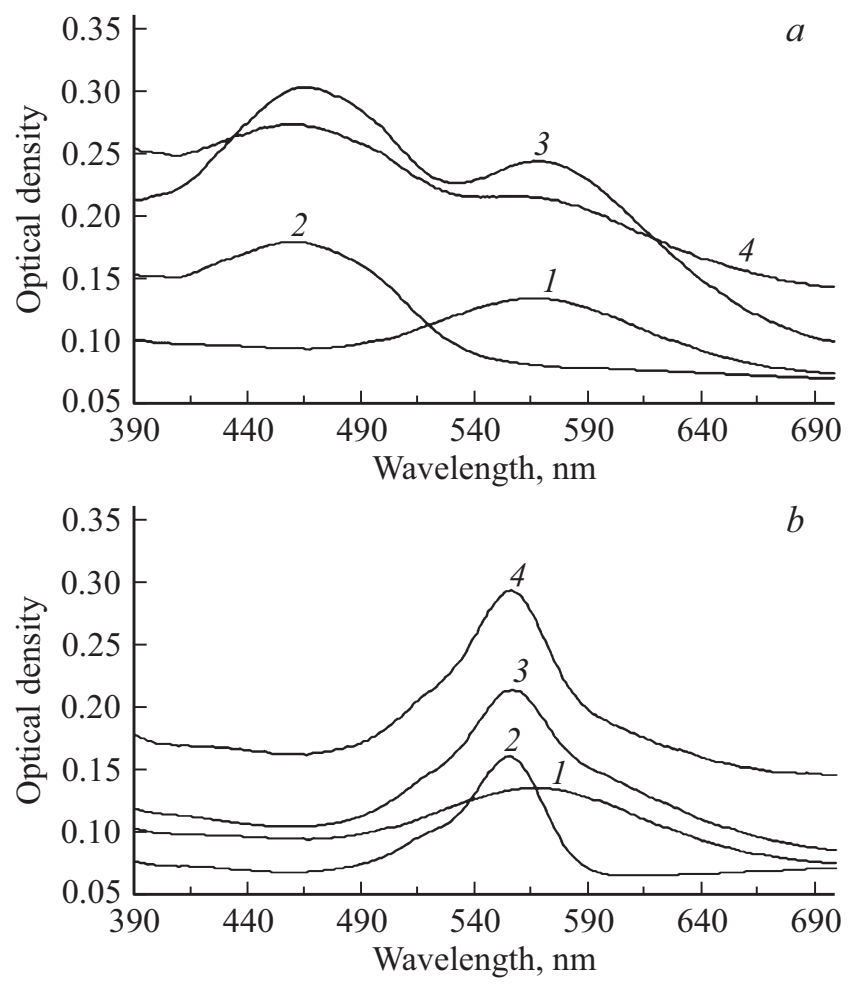

Рис. 1. (a) Спектры оптического поглощения DSM в полимерной матрице в отсутствие и при наличии плазмонного резонанса тонкой пленки золота $(\mathrm{Au}): 1-\mathrm{Au}, 2-\mathrm{DSM}$, 3 - DSM + Au, 4 - сумма спектров 1 и 2; $(b)$ Спектры оптического поглощения Родамина В (RB) в полимерной матрице в отсутствие и при наличии плазмонного резонанса тонкой пленки золота $(\mathrm{Au}): 1-\mathrm{Au}, 2-\mathrm{RB}, 3-\mathrm{RB}+\mathrm{Au}$, 4 - сумма спектров 1 и 2 . 

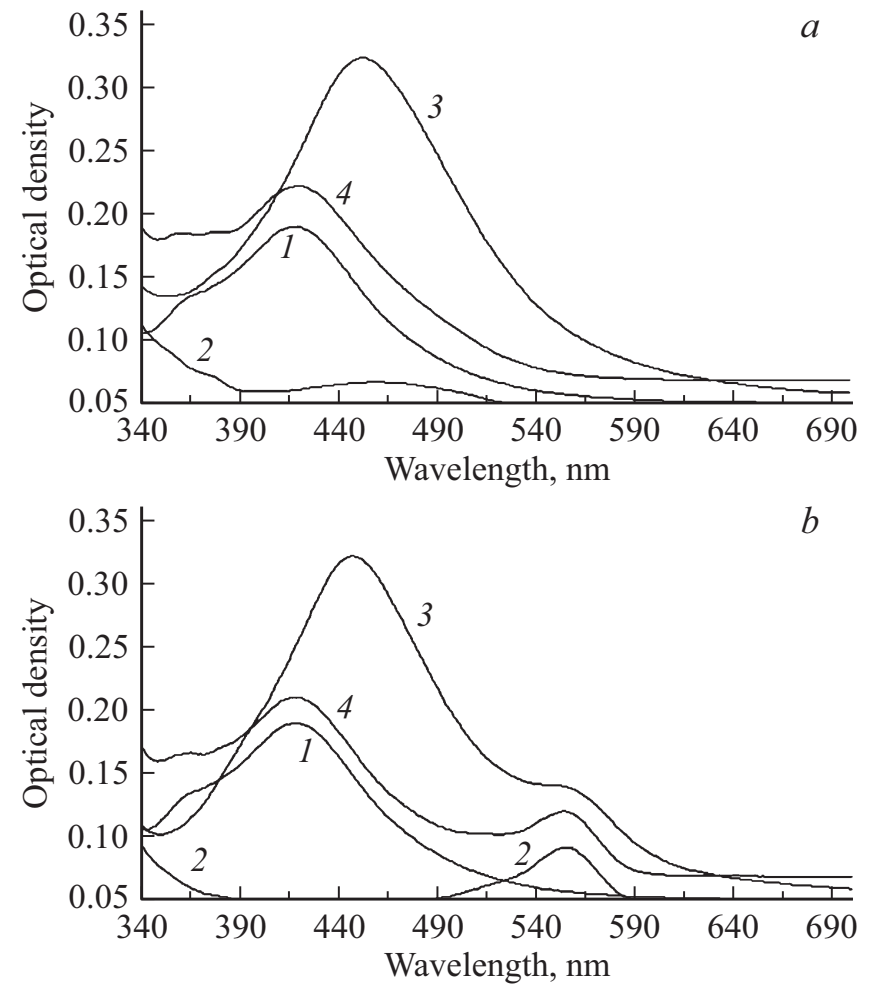

Pис. 2. (a) Спектры оптического поглощения DSM в полимерной матрице в отсутствие и при наличии плазмонного резонанса тонкой пленки серебра $(\mathrm{Ag}): 1-\mathrm{Ag}, 2-\mathrm{DSM}$, 3 - DSM + Ag, 4 - сумма спектров 1 и 2; (b) Спектры оптического поглощения Родамина В (RB) в полимерной матрице в отсутствие и при наличии плазмонного резонанса тонкой пленки серебра $(\mathrm{Ag}): 1-\mathrm{Ag}, 2-\mathrm{RB}, 3-\mathrm{RB}+\mathrm{Ag}$, 4 - сумма спектров 1 и 2 .

Приведенные на рис. $1, b$ спектры, напротив, демонстрируют, что при практически полном совпадении полос поглощения красителя RB и тонкой пленки золота увеличение поглощения не наблюдается.

Чтобы уточнить этот эффект, помимо тонких пленок золота эксперименты с этими же красителями были проделаны с тонкими пленками серебра. Представленные на рис. 2, $a$ и $2, b$ спектры оптической плотности, как и в случае пары DSM и $\mathrm{Au}$, не сводятся к сумме поглощений, а превосходят ее почти в 2 раза в обоих случаяX.

Усиление поглощения обычно связывается с двумя факторами. Первый - это усиление ближнего поля наночастиц, образующих тонкую пленку, которое способствует многократному увеличению поглощения. Второй эффект связан с зависимостью поглощения наночастиц от показателя преломления окружающего вещества и зависимостью сечения поглощения частиц от частоты. Наблюдающийся на рис. $1, b$ результат, по нашему мнению, является комбинацией обоих эффектов, которые практически нивелируют друг друга. Нанесение полимерной пленки заставляет частич- но смещаться плазмонные резонансы золотых частиц, при этом сечение их поглощения на данных частотах, как правило, меньшее. Вместе с тем рост поглощения молекул при этом возможен, но зарегистрировать его путем измерения оптической плотности невозможно. Поэтому обратимся к спектрам флуоресценции.

Представленные на рис. 3, $a$ спектры флуоресценции пары DSM и пленки $\mathrm{Au}$ демонстрируют четкое усиление флуоресценции полимерной пленки с красителем. Величина флуоресценции невелика, поскольку максимальный квантовый выход флуоресценции DCM составляет 43.5\% [10]. Кроме того, поскольку ближнее поле действует лишь на незначительную часть молекул (около $100 \mathrm{~nm}$ ), то усиление ожидаемо невелико - в 2 раза. Аналогичный результат наблюдается для пары пленки DSM и Ag-пленки на рис. 3, $b$. Отметим, что в обоих случаях частоты плазмонных резонансов или совпадают с частотами молекулярного поглощения или больше них.

Обратимся к паре RB-Au-пленка. Из рис. 4, $a$ видно, что в присутствии плазмонного резонанса флуоресценция увеличена практически в 7 раз. Отметим, что поглощение для данной пары образцов практически одинаково. Усиление флуоресценции косвенно подтверждает правильность предложенной нами интерпретации. Нако-
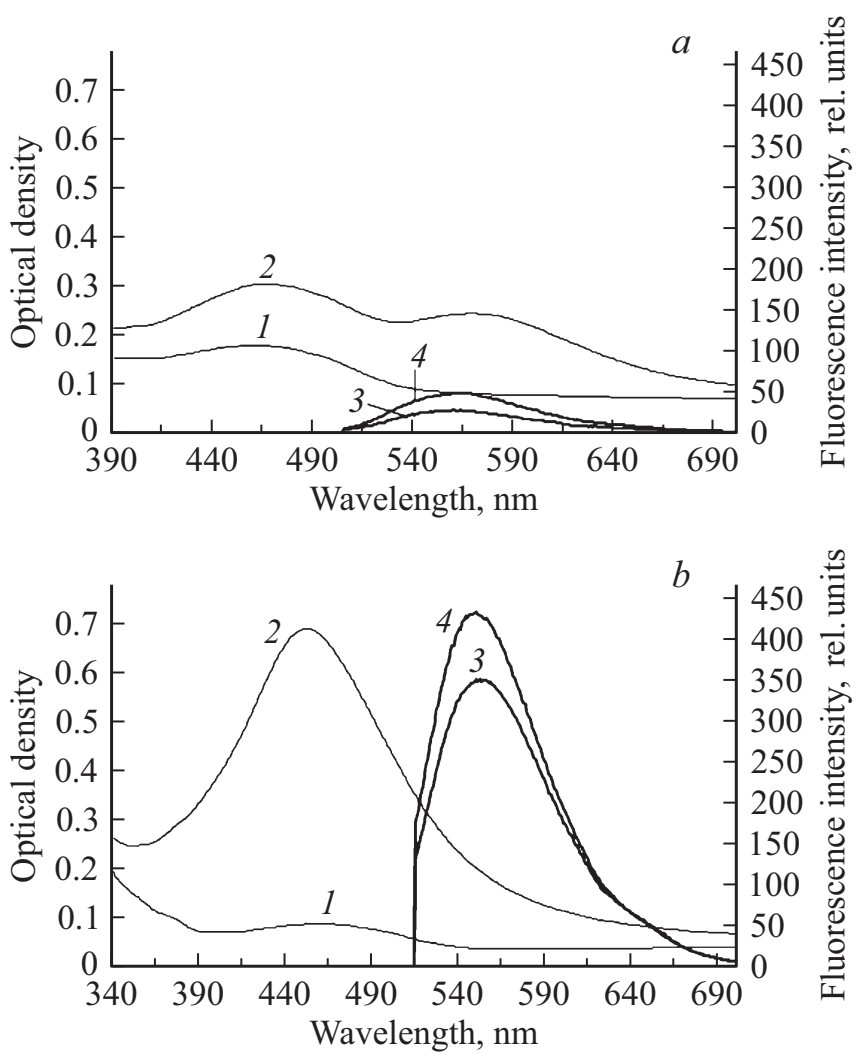

Рис. 3. Спектры оптического поглощения $(1,2)$ и флуоресценции $(3,4)$ DSM в полимерной матрице в отсутствие $(1,3)$ и при наличии $(2,4)$ плазмонного резонанса тонкой пленки золота $(a)$ или серебра $(b)$. 

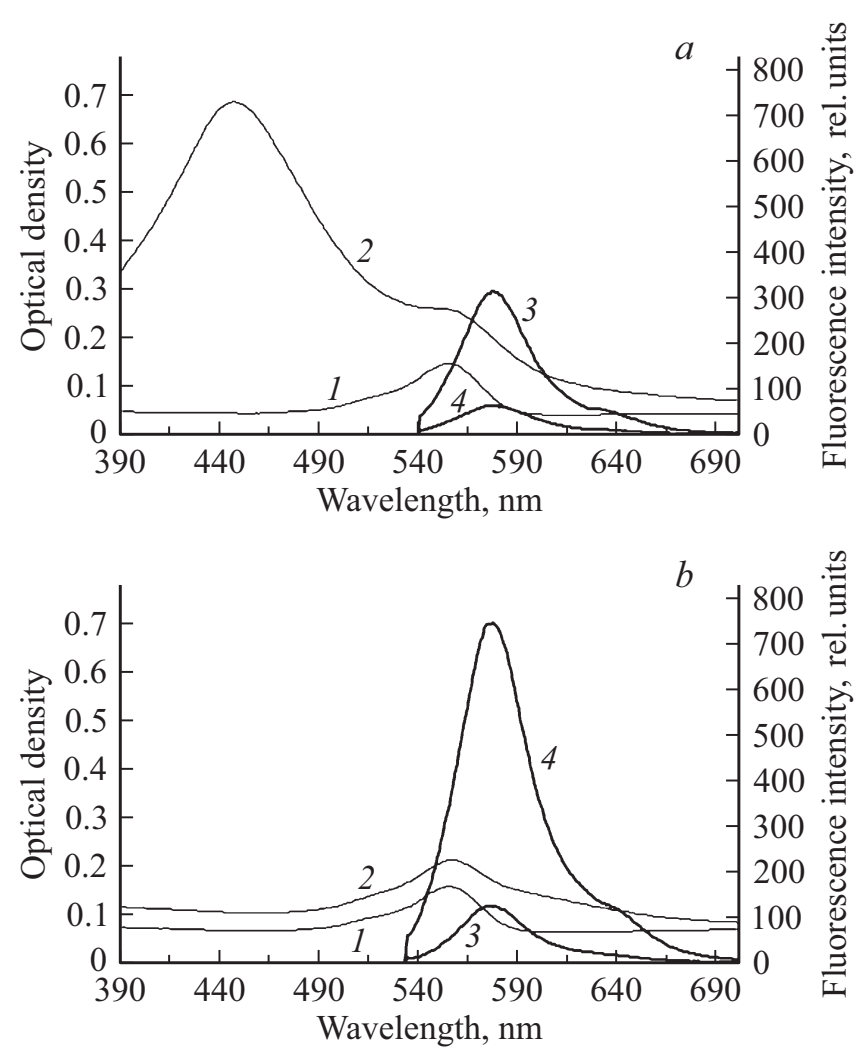

Рис. 4. Спектры оптического поглощения $(1,2)$ и флуоресценции $(3,4)$ Родамина В $(\mathrm{RB})$ в полимерной матрице в отсутствие $(1,3)$ и при наличии $(2,4)$ плазмонного резонанса тонкой пленки золота $(a)$ или серебра $(b)$.

нец, для пары RB и частиц $\mathrm{Ag}$ наблюдается тушение люминесценции (рис. $4, b$ ).

\section{Заключение}

Обобщая полученные данные, можно сделать вывод, что в случае совпадения частот плазмонного поглощения и молекулярного поглощения красителей, помещенных в акрилатную матрицу, либо в случае если частоты локализованных плазмонов незначительно больше, наблюдается усиление люминесценции красителей в ближнем поле наночастиц. В случае, когда полоса поглощения красителя смещена в красную область относительно поглощения частиц, наблюдается лишь тушение флуоресценции металлической поверхностью. Таким образом, усиление флуоресценции естественно связать с резонансным воздействием металлических наночастиц, выполняющих роль резонаторов, на флуоресцентные квантовые переходы, или эффектом Парселла. Однако такая интерпретация требует дальнейшего исследования кинетики затухания люминесценции, которая будет выполнена нами в будущем.

\section{Список литературы}

[1] Lu W., Zhong B., Ma D. // Appl. Optics. 2004. V. 43. N 26. P. 5074.

[2] Kamalieva A.N., Toropov N.A., Vartanyan T.A. // Proc. SPIE. 2016. V. 9884 . P. 98843.

[3] Galanzha E.I., Weingold R., Nedosekin D.A., Sarimollaoglu M., Nolan J., Harrington W., Kuchyanov A.S., Parkhomenko R.G., Watanabe F., Nima Z., Biris A.S., Plekhanov A.I., Stockman M.I., Zharov V.P. // Nature Commun. 2017. V. 8. N 15528.

[4] Huang Q., Zhan X., Hou Zh., Chen Q., Xu H. // Optics Commun. 2015. V. 362. P. 73.

[5] Lee J., Pang Y. // J. Nanoscience and Nanotechnology. 2016. V. 16. P. 1629.

[6] Toropov N.A., Kamalieva A.N., Vartanyan T.A. // International Journal of Nanotechnology. 2016. N 13(8-9). P. 642-647.

[7] He D., Bao W., Long L., Zhang P., Jiang M., Zhang D. // Optics \& Laser Technol. 2017. V. 91. P. 193.

[8] Zulina N.A., Pavlovetc I.M., Baranov M.A., Kaliabin V.O., Denisyuk I.Y. // Appl. Phys. A: Materials Science and Processing. 2017. V. 123. N 1. P. 39.

[9] Toropov N.A., Parfenov P.S., Vartanyan T.A. // J. Phys. Chem. C. 2014. V. 118. P. 18010.

[10] Rurack K., Spieles M. // Analytical Chem. 2011. V. 83 N 4. P. 1232. 